\title{
Single-Operator Pancreatoscopy for Diagnosis, Evaluation, and Staging of Mixed-Type Intraductal Papillary Mucinous Neoplasm
}

\author{
Rui Morais Filipe Vilas-Boas João Santos-Antunes Pedro Pereira \\ Guilherme Macedo
}

Gastroenterology Department, Centro Hospitalar São João, Porto, Portugal

\section{Keywords}

Intraductal papillary mucinous neoplasm · Pancreatoscopy · Pancreatic ductal adenocarcinoma

\section{Pancreatoscopia por Spylgass para diagnóstico, avaliação e estadiamento da neoplasia mucinosa papilar intraductal do tipo misto}

\section{Palavras-Chave}

Neoplasia mucinosa papilar intraductal .

Pancreatoscopia - Adenocarcinoma ductal pancreático

An 84-year-old man with previous history of arterial hypertension and aortic valve stenosis underwent an abdominal computed tomography due to abdominal pain. This exam revealed a hypodense non-enhanced lesion in the head and neck of the pancreas, measuring $65 \times 37 \times$ $46 \mathrm{~mm}$. This lesion was in continuity with the ampulla of Vater and resulted in diffuse main pancreatic duct (MPD) dilation (12 $\mathrm{mm}$ in the body), suspected to represent an intraductal papillary mucinous neoplasm (IPMN) with main duct involvement. Endoscopic ultrasonography confirmed the presence of a multiseptated predominantly cystic mass in the head/neck of the pancreas (Fig. 1).

\section{KARGER}

(C) 2020 Sociedade Portuguesa de Gastrenterologia Published by S. Karger AG, Basel

Karger

Upen access

This article is licensed under the Creative Commons AttributionNonCommercial-NoDerivatives 4.0 International License (CC BYNC-ND) (http://www.karger.com/Services/OpenAccessLicense). Usage and distribution for commercial purposes as well as any distribution of modified material requires written permission.
After multidisciplinary discussion, the patient was recommended for surgery with prior pancreatoscopy to evaluate the MPD directly to help guide surgical management. The pancreatoscopy was performed using a digital single-operator peroral pancreatoscopy system (SpyGlass DS; Boston Scientific, Marlborough, MA, USA). On inspection with the duodenoscope a "fish mouth" ampulla was observed (Fig. 2). After MPD cannulation using a sphincterotome, contrast instillation revealed a diffusely dilated duct (Fig. 3). Given the diffuse and important dilation of the duct it was possible to pass the 10-Fr SpyScope ${ }^{\mathrm{TM}}$ through the wire up to the tail and inspect the duct during withdrawal. When it is necessary to advance the SpyScope ${ }^{\mathrm{TM}}$ again we usually reinsert the wire to facilitate scope advancement while maintaining a stable position of the duodenoscope. Pancreatoscopy showed a scarring appearance with friability in the MPD, at the level of the pancreatic tail and body. In the neck and head, we observed the presence of mucin, papillary fronds, and projections with a "fish-egg" like appearance (Hara classification type 2; Fig. 4). We combined the pancreatoscopy image with the fluoroscopic control, taking the relation of the pancreas with the spine as an anatomical reference for the different pancreatic sections, which allowed us to understand the position of the scope inside the duct. 
Fig. 1. Endoscopic ultrasonography image with a multiseptated predominantly cystic mass in the head/neck of the pancreas.

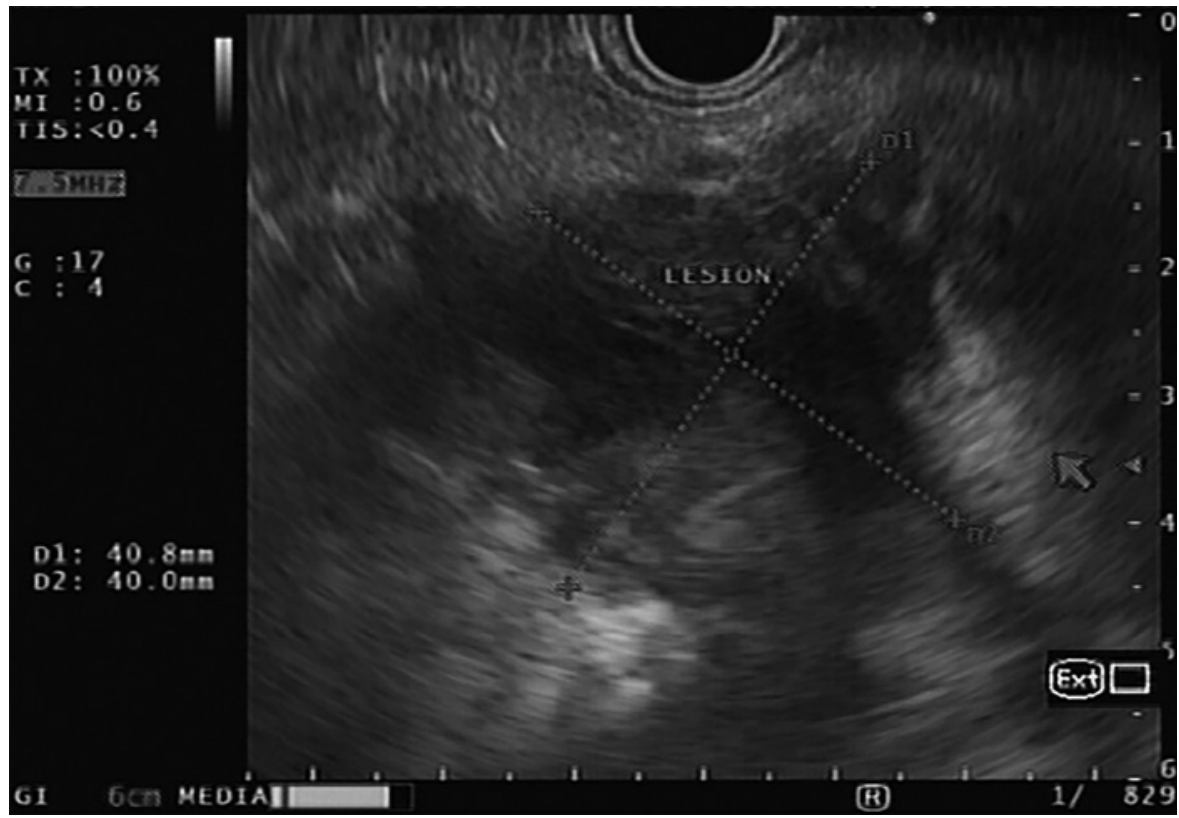

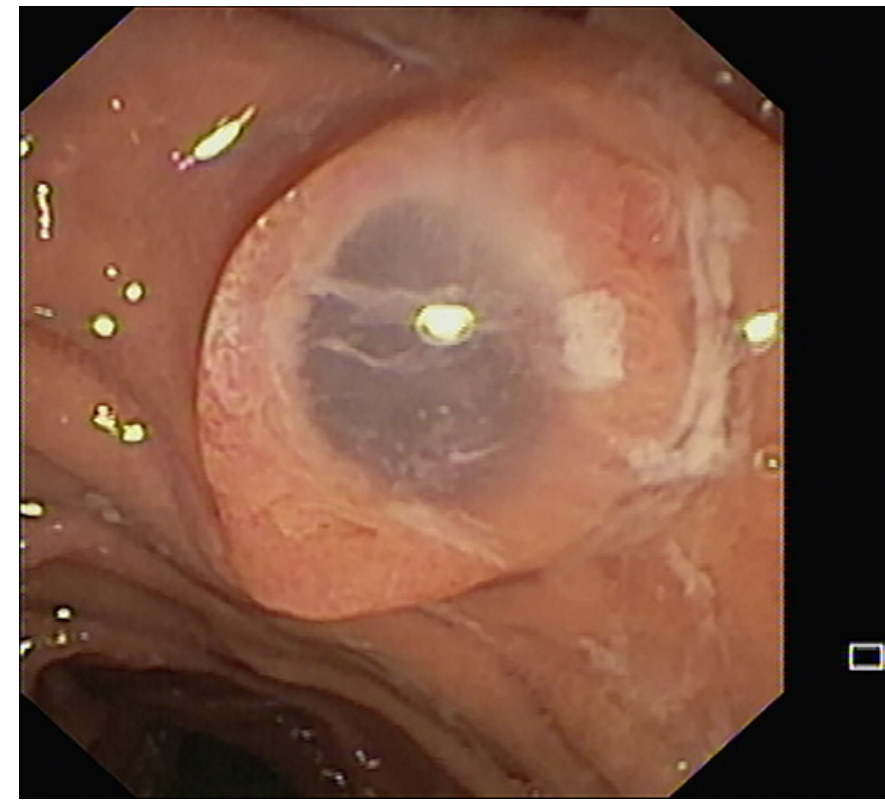

Fig. 2. Endoscopic image of "fish mouth" ampulla.

Biopsies using SpyBite ${ }^{\mathrm{TM}}$ forceps were performed in the different MPD segments (at least 3 samples per segment). SpyBite ${ }^{\mathrm{TM}}$ was passed along the accessory channel of the scope after removal of the wire. We usually lubricate the forceps using silicone spray to facilitate the passage. The

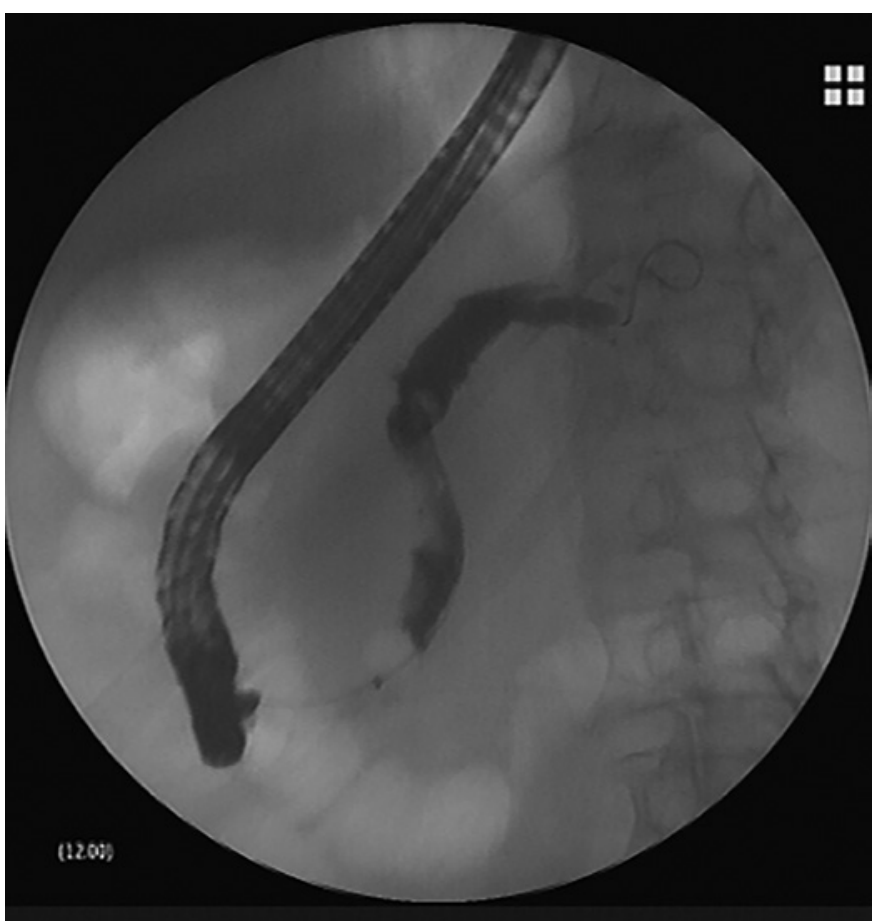

Fig. 3. Fluoroscopic image after contrast instillation with diffuse MPD dilation.

SpyScope ${ }^{\mathrm{TM}}$ dials were kept in a neutral position to avoid bending that hinders advancement of the forceps. The pathology examination revealed lesions with papillary architecture and intestinal phenotype in the head and neck, consistent with IPMN with low-grade dysplasia. No le- 
Fig. 4. Pancreatoscopy image showing the presence of mucin in the head and neck of the pancreas, papillary fronds, and protrusions with a "fish-egg" appearance.

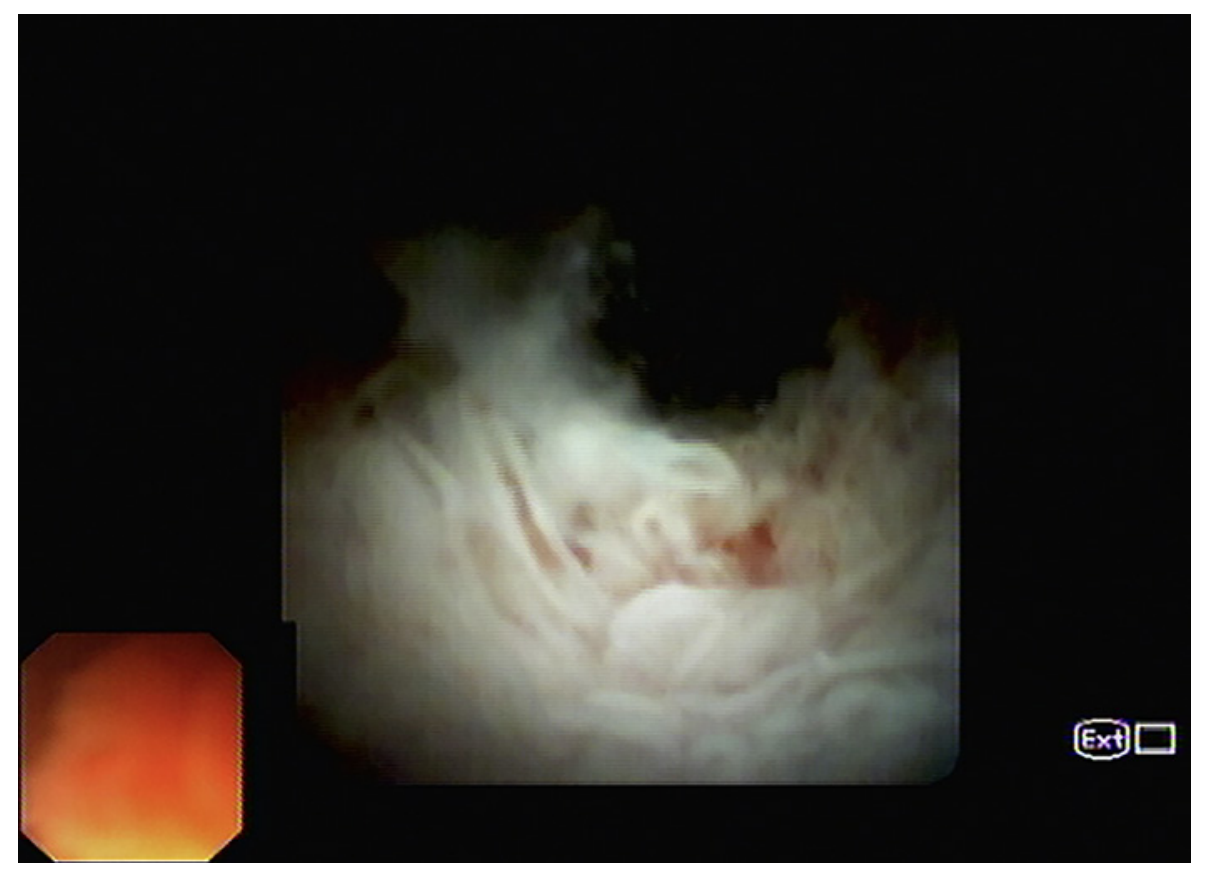

sions were observed in the biopsies performed in the body and tail region. The patient was submitted to a subtotal duodenopancreatectomy. Surgical specimen histology confirmed the previously reported findings and associated presence of a focal ductal adenocarcinoma, with 15 $\mathrm{mm}$ of extension (pT1bN0R0). The patient remains well 1 year after surgery, with no evidence of disease recurrence in the follow-up.

IPMN is a condition with a malignant potential, with varying degrees of dysplastic changes that may eventually progress to invasive carcinoma $[1,2]$. The mean frequency of invasive carcinoma and HGD in main duct (MD)IPMN is $61.6 \%$, with current guidelines from international societies recommending surgical resection for all patients fit for surgery $[3,4]$. Few studies have investigated mixed-type (MT)-IPMN as a single entity, although malignancy rates appear in line with MD-IPMN [5].

Therapeutic decisions regarding IPMN can be challenging, since the assessment of the extent of malignancy and obtaining a definite diagnosis can often be difficult [6]. Total pancreatectomy provides the most complete oncologic resection, but postoperative morbidity and impact in quality of life associated with this procedure is significant [7]. A recent study reported overtreatment or too extensive resection of MD-IPMN in 19\% of patients [8]. However, the risk of disease recurrence or progression is not negligible, with Majumder et al. [9] recently reporting a 10 -year incidence of pancreatic cancer of $21.2 \%$ in the follow-up. Current European guidelines state that pancreatoscopy may be used in selected cases to provide information on the location and extent of MD-IPMN [4]. Some studies previously evaluated the role of single-operator pancreatoscopy in the evaluation of patients with suspected IPMN, with conflicting results. Arnelo et al. [10] prospectively evaluated patients with radiological suspicion of IPMN and pancreatoscopy was judged to have provided additional information in 39 of the 41 patients (95\%), affecting clinical decisions in $76 \%$ of them. Nagayoshi et al. [11] evaluated 17 patients with IPMN, with pancreatoscopy-guided biopsies having a 25\% sensitivity and $100 \%$ specificity for detecting malignancy. Pancreatoscopy was useful in the determination of the operative excision line in 3 patients. In contrast, in a more recent study by Ohtsuka et al. [12], pancreatoscopy only changed the surgical management in 1 of 7 patients and, similarly to our case, failed to detect 1 concomitant pancreatic ductal adenocarcinoma. These data and the presented case highlight the fact that, despite there being a possible role for peroral pancreatoscopy in the preoperative assessment of MDand MT-IPMN, some questions remain, especially regarding the diagnostic ability for targeting biopsy and accurate assessment of surgical margins, meaning an intraoperative frozen section is still needed to obtain negative surgical margins [12]. More prospective studies are necessary in order to assess the specific role of this exam in the diagnostic algorithm of these lesions. 
Statement of Ethics

The authors have no ethical conflicts to disclose.

\section{Disclosure Statement}

The authors have no conflicts of interest to declare.

\section{References}

1 LaFemina J, Katabi N, Klimstra D et al. Malignant progression in IPMN: a cohort analysis of patients initially selected for resection or observation. Ann Surg Oncol. 2013;20(2): 440-7.

2 Sohn TA, Yeo CJ, Cameron JL, Hruban RH, Fukushima N, Campbell KA, et al. Intraductal papillary mucinous neoplasms of the pancreas: an updated experience. Ann Surg. 2004; 239(6):797-9.

3 Tanaka M, Fernandez-Del Castillo C, Kamisawa $\mathrm{T}$ et al. Revisions of international consensus Fukuoka guidelines for the management of IPMN of the pancreas. Pancreatology. 2017;17:738-53.

4 European Study Group on Cystic Tumours of the Pancreas. European evidence-based guidelines on pancreatic cystic neoplasms. Gut. 2018 May;67(5):789-804.

5 Tian X, Gao H, Ma Y, Zhuang Y, Yang Y. Surgical treatment and prognosis of 96 cases of intraductal papillary mucinous neoplasms of the pancreas: a retrospective cohort study. Int J Surg. 2015 Jan;13:49-53.

6 Miller CS, Chen YI. Current role of endoscopic pancreatoscopy. Curr Opin Gastroenterol. 2018 Sep;34(5):309-15.

7 Billings BJ, Christein JD, Harmsen WS, Harrington JR, Chari ST, Que FG, et al. Qualityof-life after total pancreatectomy: is it really that bad on long-term follow-up? J Gastrointest Surg. 2005 Nov;9(8):1059-66.

8 Crippa S, Pergolini I, Rubini C, Castelli P, Partelli S, Zardini C, et al. Risk of misdiagnosis and overtreatment in patients with main pancreatic duct dilatation and suspected combined/main-duct intraductal papillary mucinous neoplasms. Surgery. 2016 Apr; 159(4):1041-9.

9 Majumder S, Philip NA, Singh Nagpal SJ, Takahashi N, Mara KC, Kendrick ML, et al. High-grade dysplasia in resected main-duct intraductal papillary mucinous neoplasm (MD-IPMN) is associated with an increased risk of subsequent pancreatic cancer. Am J Gastroenterol. 2019 Mar;114(3):524-9.

10 Arnelo U, Siiki A, Swahn F, Segersvärd R, Enochsson L, del Chiaro M, et al. Single-operator pancreatoscopy is helpful in the evaluation of suspected intraductal papillary mucinous neoplasms (IPMN). Pancreatology. 2014 Nov-Dec;14(6):510-4.

11 Nagayoshi Y, Aso T, Ohtsuka T, Kono H, Ideno N, Igarashi $\mathrm{H}$, et al. Peroral pancreatoscopy using the SpyGlass system for the assessment of intraductal papillary mucinous neoplasm of the pancreas. J Hepatobiliary Pancreat Sci. 2014 Jun;21(6):410-7.

12 Ohtsuka T, Gotoh Y, Nakashima Y et al. Role of SpyGlass-DStm in the preoperative assessment of pancreatic intraductal papillary mucinous neoplasm involving the main pancreatic duct. Pancreatology. 2018;18(5):566-71. 